\title{
Study on Acoustic Emission Characteristics of a Semirigid Base of Dense Skeleton Type during Complete Uniaxial Compression Tests
}

\author{
Shengli Li, Guangming Wu, and Hao Wu \\ School of Civil Engineering, Zhengzhou University, Zhengzhou 450001, China \\ Correspondence should be addressed to Shengli Li; 1s12009@126.com
}

Received 20 May 2016; Accepted 17 July 2016

Academic Editor: Ying Wang

Copyright (C) 2016 Shengli Li et al. This is an open access article distributed under the Creative Commons Attribution License, which permits unrestricted use, distribution, and reproduction in any medium, provided the original work is properly cited.

\begin{abstract}
Acoustic emission testing of semirigid base specimens subjected to uniaxial compression was performed by a mechanical testing machine and $\mathrm{AE}$ system to find the $\mathrm{AE}$ criterion of the uniaxial compressive failure process of the semirigid base of dense skeleton types. AE counts, cumulative AE energy, and $b$-value were discussed. Results indicated that the AE parameters could reflect the failure process of semirigid bases of dense skeleton types. The failure process mainly underwent three stages that were divided based on $\mathrm{AE}$ parameters into initial stage of development, stable growth stage, and unstable stage. The knees of the AE parameter curve were at $25 \%$ and $85 \%$ of the ultimate load. The variation of the $b$-value could indicate the stress and be a precursor to the failure of the specimens. In general terms, a $b$-value greater than 3.5 indicates that specimens are at the initial stage of development. A $b$-value between 1 and 2 indicates that the specimens are at the stable growth stage. If the $b$-value seems to fluctuate and increase, the specimens are at the unstable stage. Moreover, the AE parameters indicated that attaching sensors to the waist of specimens was superior to that at other locations of a specimen.
\end{abstract}

\section{Introduction}

Semirigid bases possess many advantages such as high strength, good integrity, and low cost. Semirigid bases are used in the vast majority of high-grade asphalt pavements in China. Roads usually experience overload, and road damage that affects the normal operation of roads is a common occurrence. Applying nondestructive testing to road damage is essential in predicting the occurrence of road damage in advance, reducing the cost of road maintenance, and ensuring the normal operation of roads.

At present, ground penetrating radar (GPR) is the primary nondestructive detection method for road diseases. The GPR can easily detect a large size of disease $[1,2]$, for example, the void of road bases, but it has difficulty in detecting the crack of road bases that is a small size of disease. Acoustic emission (AE) is a propagation of elastic waves caused by the release of localized internal energy when a microfracture occurs in an elastic material [3]. An AE monitoring system can detect the development of damage of a structure under load. We can identify changes and the condition of internal material by analyzing AE signals. Application of AE detection is very extensive; for example, $\mathrm{AE}$ has been used by scholars to study rocks under compression tests [4-7]. Research indicated that the AE counts of rocks increased with the increase of the load. Scholars also studied coal under compression tests with the AE system [8-10]. The relationship between $\mathrm{AE}$ parameters and the pressure of coal specimens was analyzed. The AE parameters could identify the damage characterization of coal specimens. In studying concrete under compression cracking, $\mathrm{AE}$ parameters could identify crack propagation in concrete specimens using the AE system [11-14]. Results provided guidance in evaluating the internal damage of concrete. The decrease of the $b$-value, which changed systematically with the different stages of the fracture process of rock [15-17] and concrete [18-20] under the load, indicated that the fracture process had moved from micro- to macrocracking as the material approached impending failure. However, the AE characteristics of semirigid bases of dense skeleton types have not yet been studied. 


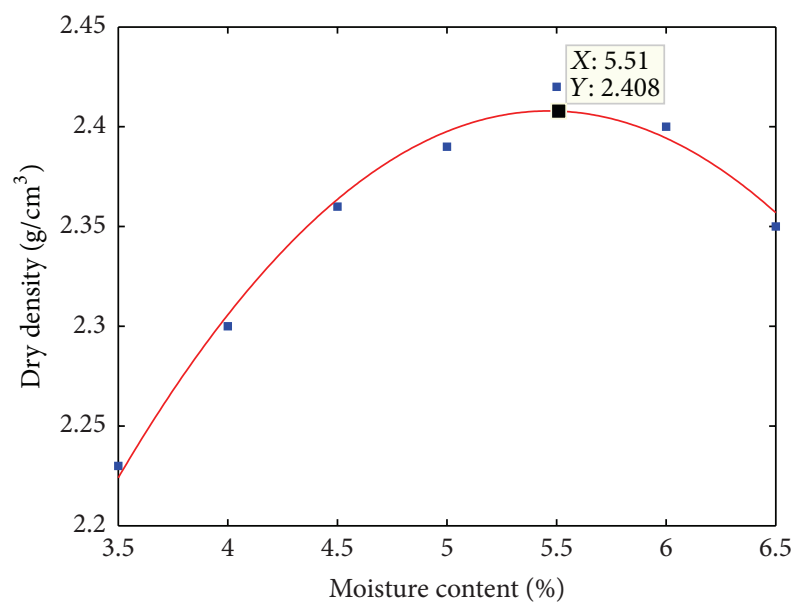

FIGURE 1: Relationship between moisture content and dry density.

Using AE requires damaging the structure under the load. The roads bear the load created by trucks; thus, we can acquire an $\mathrm{AE}$ signal when roads are being used. AE tests of semirigid base specimens subjected to uniaxial compression were conducted by using a TYE mechanical testing machine and an AE system to exploit the ability of AE to discover tiny cracks in the structure as well as to offset the shortage of GPR detected in the semirigid base asphalt pavement. AE counts, cumulative energy of AE signal waveform data, and $b$-value analysis of AE amplitude are discussed in detail. Support of $\mathrm{AE}$ detection of semirigid base of dense skeleton type was provided by the basic AE data which is discussed in this paper.

\section{Material and Experimental Procedure}

2.1. Material and Specimen Preparation. A compaction test was conducted in the laboratory to ensure optimum moisture content of semirigid mixtures. The relationship between moisture content and dry density is shown Figure 1, and optimum moisture content and maximal dry density were $5.51 \%$ and $2.41 \mathrm{~g} / \mathrm{cm}^{3}$, respectively. The six specimens of the semirigid base of dense skeleton type were made at optimum moisture content by the molding of static pressure. The cylindrical specimens with a compaction degree of $98 \%$ had a diameter of $100 \mathrm{~mm}$ and a height of $100 \mathrm{~mm}$, and the parallel of the end was under control at $\pm 0.02 \mathrm{~mm}$ for the nondestructive tests and compressive tests. The six specimens were cured for six days in a standard curing box where humidity was greater than $95 \%$ and temperature was at $20^{\circ} \mathrm{C}$ $\pm 2^{\circ} \mathrm{C}$. Then, before the compressive tests, the six specimens were cured for one day in a curing tank filled with water. The semirigid mixture was composed of water, cement, and crushed stone, and the cement dosage was $4 \%$. The design gradation of the semirigid base mixtures was determined as shown in Table 1.

2.2. Test Setup and AE Instrumentation. The compressive tests of the six specimens were performed by using the TYE mechanical testing machine with a maximum loading
TABLE 1: Design gradation of semi-rigid base mixtures.

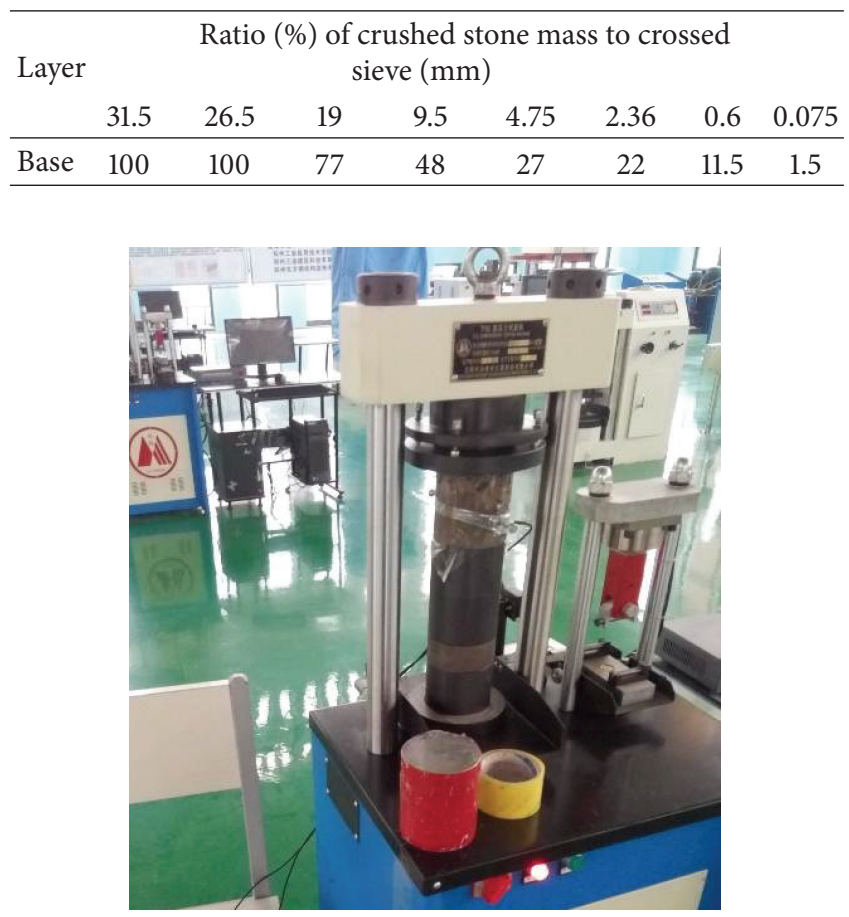

FIGURE 2: Mechanical testing machine.

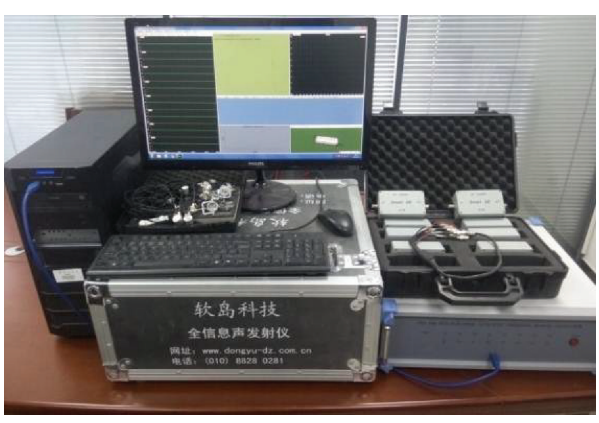

FIgURE 3: AE data acquisition system.

capacity of $300 \mathrm{kN}$ and variable loading input ranges. The $\mathrm{AE}$ signals were digitized by using an $\mathrm{AE}$ data acquisition system, which is a full-waveform data acquisition instrument. The amplitude distribution ranged from 0 to $100 \mathrm{~dB}(0 \mathrm{~dB}$ corresponds to $1 \mu \mathrm{V}$ at the sensor output). AE signals generated during the compression tests were recorded using a RS$2 \mathrm{~A}$ piezoelectric $\mathrm{AE}$ sensor along with a $40 \mathrm{~dB}$ preamplifier. AE_DS5 software was used to record and store AE waveform data with a low-pass filter $(<400 \mathrm{kHz})$. In addition, the sampling rate was $2.5 \mathrm{MHz}$, and an $\mathrm{AE}$ trigger threshold of $35 \mathrm{~dB}$ was used in AE_DS5 to remove the background noise. The TYE mechanical testing machine and AE data acquisition system are shown in Figures 2 and 3, respectively.

2.3. Experimental Procedure. Two schemes for sensor layout were used to comprehensively examine the AE characteristics of the semirigid base of dense skeleton type. The position 


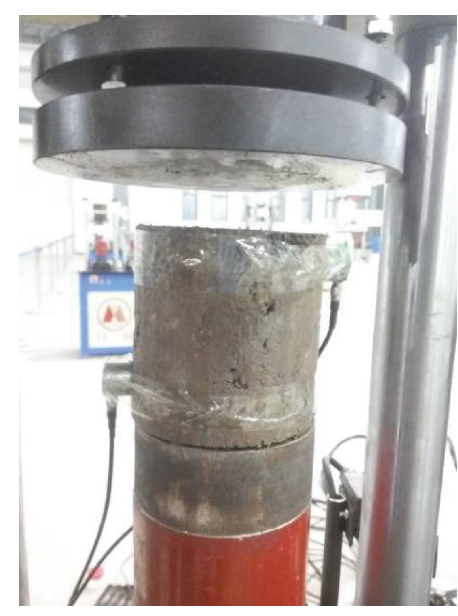

(a)

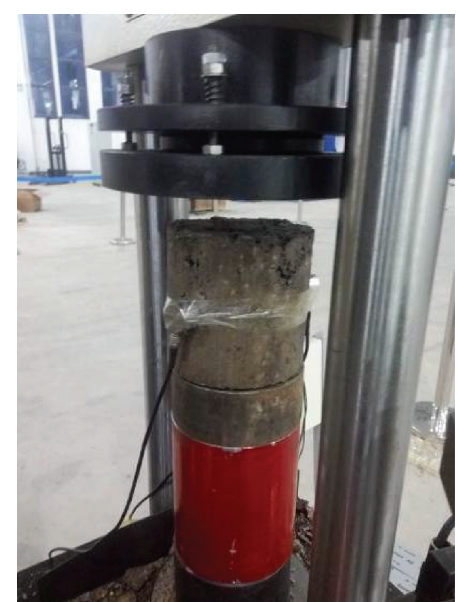

(b)

FIGURE 4: Schemes for sensor layouts: (a) sensors fixed in the middle of specimen and (b) sensors fixed on the end of specimen.

for laying sensors is shown in Figure 4. Vaseline was applied between the sensors and the specimen surface to improve AE coupling. The sensors were also secured by plastic tape to ensure that they would remain in place. The load was applied with a pressure rate of $0.39 \mathrm{kN} / \mathrm{s}$ to reduce the noise of the machine. The signal-to-noise ratio levels were improved by the instrument. The frequency of noise obtained from AE waveform by fast Fourier transform is lower than $4 \mathrm{kHz}$. The noise processing method is band-pass filtering, whose bandwidth is $5-400 \mathrm{kHz}$. The reasonable analysis parameter of AE_DS5 was set to minimize the noise effect to obtain more accurate results. Through multiple comparisons of processing results, the fixed threshold was set at $40 \mathrm{~dB}$. Peak definition time (PDT), hit definition time (HDT), and hit lockout time (HLT) were 150,300 , and $500 \mu$ s, respectively. The experimental process is shown in Figure 5.

\section{Results}

The six specimens taken for the uniaxial compression test were divided into two groups corresponding to the two schemes for sensor layouts. Two channels were used to collect the AE signals generated as the specimens cracked. The result of each channel was similar in the same scheme. One channel of data in a group was analyzed in this paper. According to the AE parameter characteristic and the stress characteristic, the failure process of specimens mainly underwent three stages: an initial stage of development (early period of loading), a stable growth stage (middle period of loading), and an unstable stage (end period of loading). The relations between AE hits and the stress level of the specimens under monotonic loading are indicated in Figures 6 and 7. The stress is normalized by peak stress to discuss the relations between stress level and AE parameters of specimens.

\subsection{AE Counts Analysis}

3.1.1. Sensor Fixed on End of Specimen. As shown in Figure $6(\mathrm{a}), \mathrm{AE}$ counts rose quickly and continuously when the stress of specimens was low. AE counts were relatively continuous and remained constant at a low level when the specimens were in the middle period of loading. Then, the AE counts increased rapidly at the final stress level. During the early period of loading, the AE counts escalated along with the increase of stress. At $7 \%$ of peak stress, the $\mathrm{AE}$ counts reached a short peak and then recovered calm. The AE generated was clearly active at low stress level of the specimen (relative stress less than 10\%). The inside of specimens could not generate cracks because the stress was small. For the mixture of cement-stabilized macadam, original defects, for example, original microcracks, were generated unavoidably inside the specimens because of dry shrinkage, poor cementing materials, and so on. The original microcracks cracked because of stress concentration as the load on the specimens increased, and the AE events were generated by strain energy release. Therefore, during the early period of loading, the cracking of the original microcracks was the AE source. The specimens entered the middle period of loading as the stress increased. AE counts became few and relatively continuous, but the AE amplitude was larger than it was during the early period of loading, as shown in Figure 7(a). This figure indicates that the internal portion of specimens generated small microcracks as the stress increased; but the new microcracks were relatively stable and growth was slow at this stage. During the end period of loading, AE counts increased rapidly, and the specimens entered a critical state of ultimate bearing capacity. This result indicated the growth, propagation, and interconnection of new microcracks. Then, the interlocking effect of coarse aggregates disappeared, and the specimens were unstable and damaged.

3.1.2. Sensor Fixed in the Middle of Specimen. Figure 6(b) shows that the specimens generated few AE events at the initiation of compression. Then, AE counts increased quickly when the relative stress of specimens was between $15 \%$ and $25 \%$. This observation implies that the original internal defects deteriorated as the relative stress was between $15 \%$ 


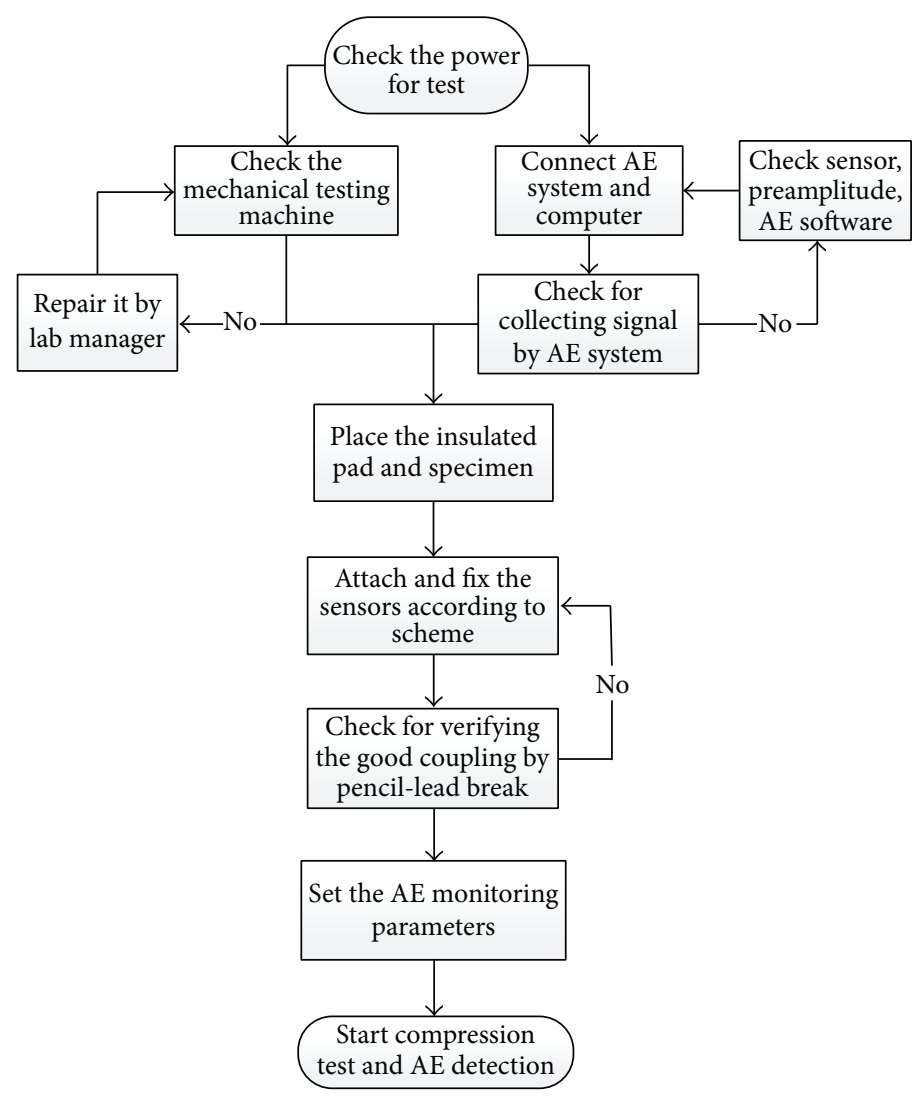

FIGURE 5: AE test process.

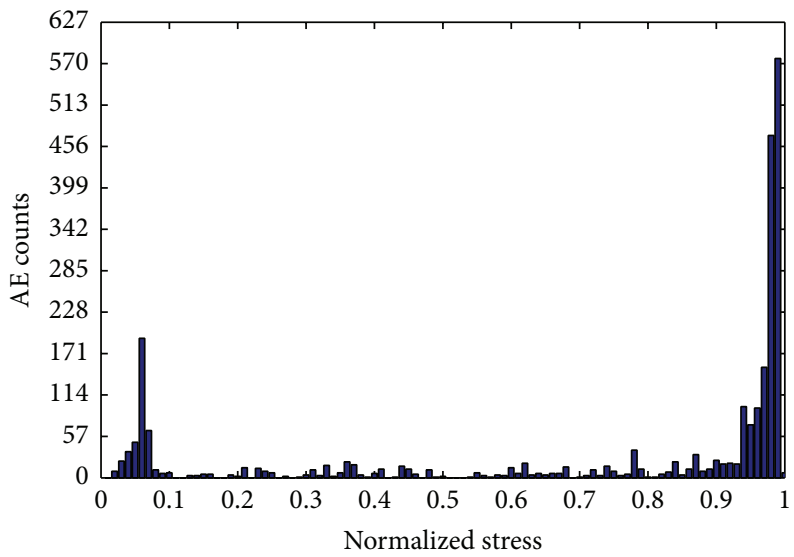

(a)

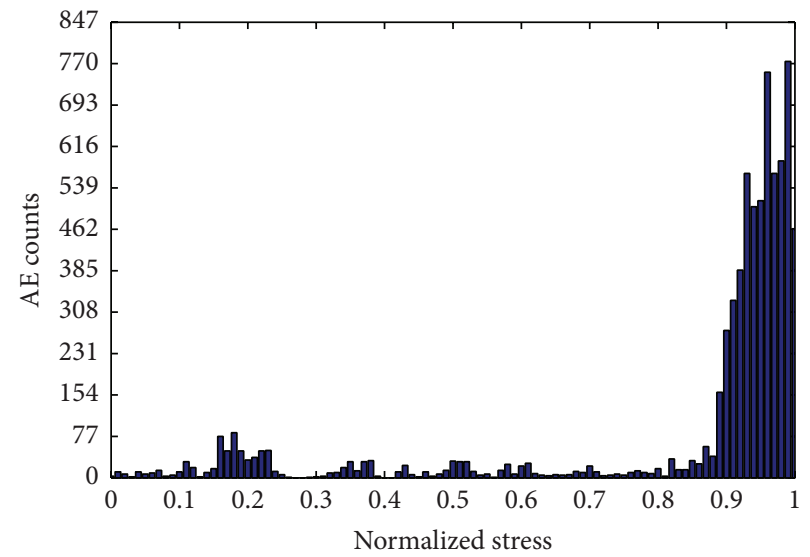

(b)

FIGURE 6: Variation of AE counts with relative stress: (a) sensor fixed on the end of specimen and (b) sensor fixed in the middle of specimen.

and $25 \%$. During the middle period of loading, AE counts were continuous and remained low. Cumulative AE counts at this stage were equal to those in the early period of loading. This phenomenon can be explained that the degree of specimen damage during the middle period of loading is equal to the degree of specimen damage in the early period of loading. During the end period of loading, AE counts increased rapidly and lasted for a long time. This result indicates microcrack propagation and the generation of numerous new microcracks that interconnected to become macrocracks. Then, the specimens lost carrying capacity.

3.2. Cumulative AE Energy Analysis (AE Signal Strength Analysis). AE energy is regarded as the area under the purified AE signal and over the duration of the AE waveform packet. It is generally referred to as relative energy, which relates to the amount of energy released by the material. 


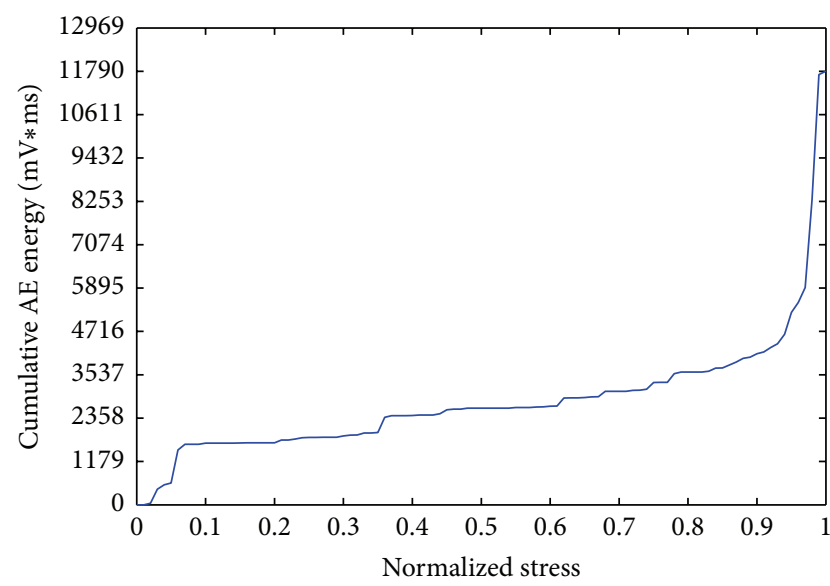

(a)

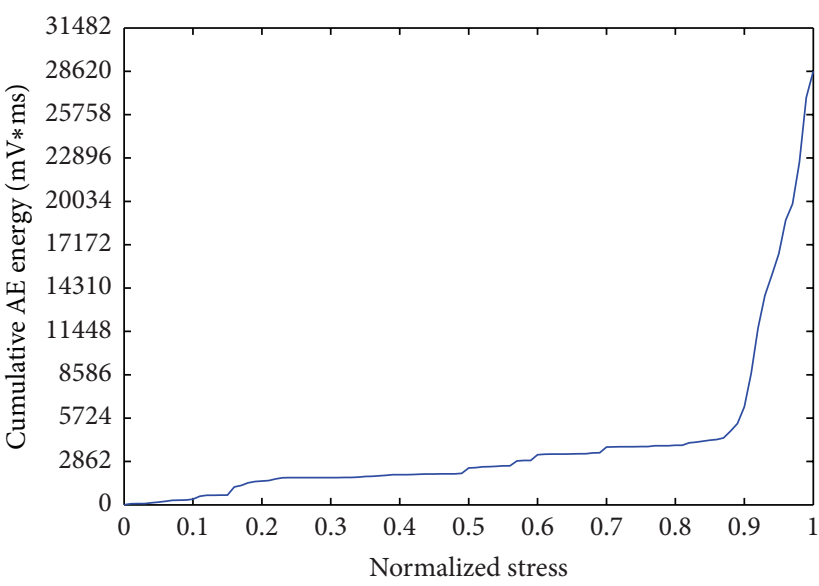

(b)

FIGURE 7: Variation of cumulative AE energy with relative stress: (a) sensor fixed on the end of specimen and (b) sensor fixed in the middle of specimen.

The cumulative AE energy data obtained from the specimens tested in this study are plotted in Figure 7.

3.2.1. Sensor Fixed on the End of Specimen. Figure 7(a) shows that, prior to the relative stress of $10 \%$, cumulative $\mathrm{AE}$ energy obtained from the specimens increased quickly with the increase of stress, and it reached approximately $15 \%$ of the final value. The variation of the curve corresponded to the deterioration of the original defects. The slope of cumulative $\mathrm{AE}$ energy was flat, and the step phenomenon occasionally occurred during the middle period of loading. The increase of cumulative AE energy was estimated as equal to that in the previous stage. With the increase of load to the end period, the cumulative AE energy data curve ascended sharply and attained its maximum, indicating the failure of the specimen.

3.2.2. Sensor Fixed in the Middle of Specimen. Figure 7(b) shows that the cumulative AE energy increased gradually at the very beginning of the stress increase. The cumulative $\mathrm{AE}$ energy curve bent, and the slope of the curve was larger at the relative stress of $15 \%$. The cumulative AE energy increased to $10 \%$ of total AE energy when the relative stress increased to $25 \%$. The increment rate and increment of cumulative $\mathrm{AE}$ energy were inconspicuous during the middle period of loading, which indicates that few cracks were generated. At the relative stress of $85 \%$, the curve abruptly steepened. This result indicates the propagation of microcracks and their interconnecting to form macrocracks. Then, the specimens lost carrying capacity.

3.3. b-Value Analysis Based on AE Amplitude. AE amplitude, expressed usually with unit of $\mathrm{dB}$, is regarded as the peak value of the $\mathrm{AE}$ waveform packet. The parameter reflects the strength of an $\mathrm{AE}$ event. In this paper, $\mathrm{AE}$ amplitude characteristics are described by the $b$-value in the field of seismology. The $b$-value is a parameter defined originally by Gutenberg and Richter to estimate the likelihood of the occurrence of earthquakes above a specified magnitude $M$ [17]. The G-R equation is as follows:

$$
\log _{10} N=a-b M,
$$

where $M$ is the Richter magnitude of earthquakes, $N$ is the number of earthquakes with magnitude greater than $M, a$ is an empirical constant, and $b$ is the slope, which is a linear relationship fitted between the magnitude of earthquakes and incremental frequency. However, the AE phenomenon is similar to an earthquake. Therefore, to apply the $b$-value to $\mathrm{AE}$, the $\mathrm{G}-\mathrm{R}$ formula is modified as follows:

$$
\log _{10} N=a-b\left(\frac{A_{\mathrm{dB}}}{20}\right),
$$

where $N$ is the incremental frequency (i.e., the number of $\mathrm{AE}$ hits with an amplitude greater than the threshold $A_{T}$ ), $a$ is an empirical constant, and $b$ is the $b$-value that is defined as the log-linear slope of the cumulative amplitude distribution of $\mathrm{AE}[17,21,22]$.

3.3.1. Sensor Fixed on the End of Specimen. As shown in Figure 8(a), the $b$-value was a large number above 4 in the initial stages at which the relative stress ranged between $8 \%$ and $25 \%$. With the increase in stress between $25 \%$ and $40 \%$, the $b$-value decreased to less than 2 . However, the $b$-value of $\mathrm{AE}$ hits commonly remained constant below 2 when the relative stress was larger than $40 \%$. Finally, the relative stress rose to $85 \%$, and the $b$-value began to fluctuate and enlarge.

3.3.2. Sensor Fixed in the Middle of Specimen. As shown in Figure $8(\mathrm{~b})$, the shape of the curve is similar to that plotted in Figure 8(a). The $b$-value was a large number above 3.5 in the first instance where the relative stress was below $25 \%$. However, it subsequently decreased and reached approximately 1.5 when the relative stress reached $60 \%$. The $b$-value had almost no change until $90 \%$ of the relative stress. At the final stage, the $b$-value fluctuated and increased as expected. 


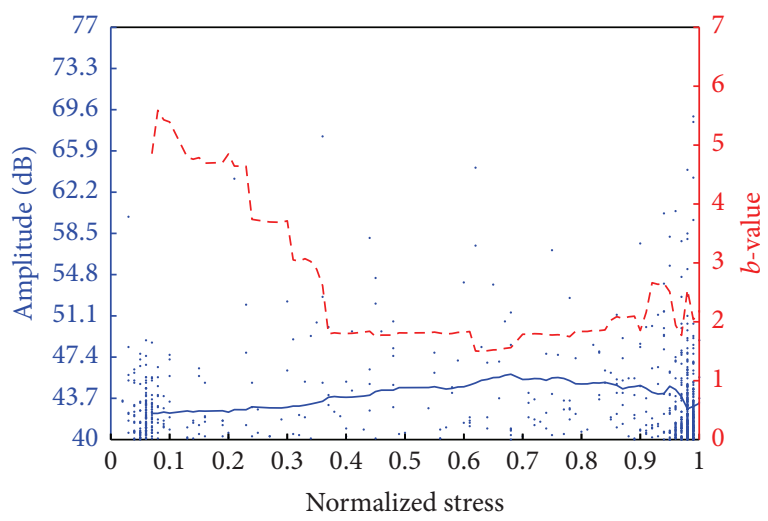

$\begin{array}{ll} & \text { Amplitude } \\ - & b \text {-value } \\ - & \text { Averaged amplitude }\end{array}$

(a)

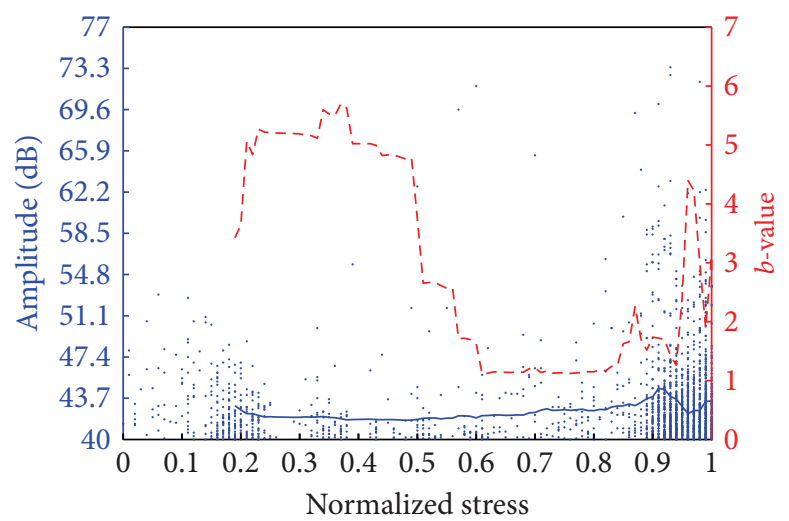

Amplitude

$\begin{array}{ll}-- & b \text {-value } \\ - & \text { Averaged amplitude }\end{array}$

(b)

FIGURE 8: Variation of $b$-value: (a) sensor fixed on the end of specimen and (b) sensor fixed in the middle of specimen.

As Figure 8 shows, the $b$-value for estimating the semirigid base of dense skeleton type throughout the uniaxial compression tests changed schematically at different stages of fracture in specimens. The changes of $b$-value were concluded to four stages: early stage, where the $b$-value was large; middle stage, where the $b$-value gradually decreased; middle stage, where the $b$-value remained constant; and last stage, where the $b$-value increased again. For the mixture of cementstabilized macadam, in the early stage, the energy of cracking of the original microcracks was small and the AE amplitude of weak elastic wave was less than $48 \mathrm{~dB}$ (the mean amplitude of $100 \mathrm{AE}$ events was approximately $42.5 \mathrm{~dB}$ ). Thus, the $b$ value based on the $\mathrm{AE}$ amplitude was large and generally larger than 3.5. In the middle stage of reducing value, the rate of $\mathrm{AE}$ hit was slow, and the $\mathrm{AE}$ data in the previous stage was used to calculate the $b$-value defined as the loglinear slope of the cumulative amplitude distribution of AE. However, the amplitude of AE generated by new internal cracks in the middle period of loading was larger; therefore, the $b$-value decreased with the increase in load, and this process was marked to the middle stage of reducing value. With the increase of stress, the accumulation of AE hits during the middle stage was enough to fit out the slope ( $b$-value). Furthermore, the $b$-value was now stable without the effect of stress. In reality, all AE hits to fit out the $b$ value originated from the middle period of loading. Thus, the $b$-value in the middle stage of constant value was more prominent in the estimation for the condition of damage than in the middle stage of reducing value. In the middle period of loading, the original microcracks had cracked and the stress had been redistributed. With the increase in stress, the new crack generated AE hits whose amplitude was greater than $48 \mathrm{~dB}$; thus, the $b$-value ranged between 1 and 2 . In the end period of loading, numerous AE hits were recorded by sensors along with the occurrence of structural cracks of specimens. However, the ratio of low amplitude increased because of weak cementation of material; thus, the $b$-value was fluctuant and increased with the increase in stress.

\section{Discussion}

The AE characteristics of two different schemes for sensor layouts were qualitatively similar but still different to a certain extent. They are described as follows.

Similarity. According to the AE counts characteristic and cumulative AE energy characteristic versus stress, the failure process of specimens underwent three main stages: initial stage of development (early period of loading), stable growth stage (middle period of loading), and unstable stage (end period of loading). The initial stage of development lasted for a short period and the stable growth stage lasted for a long period, but the increments of AE counts in the two stages were almost equal, as well as the increments of cumulative AE energy. However, at the unstable stage, the AE counts and cumulative AE energy increased sharply. In addition, the $b$ value was categorized into four stages: the early stage with a large value, the middle stage with a reducing value, the middle stage with a constant value, and the last stage with an increasing value. The $b$-value was greater than 3.5 in the early stage. Then, the $b$-value was almost constant between 1 and 2 in the middle stage. Finally, the $b$-value fluctuated and increased but did not exceed 4 in the last stage of increasing value.

Differences. The AE counts and cumulative AE energy characteristics of sensors fixed on the end of specimens indicated that the end point of the initial stage of development was at $10 \%$ of peak stress, but the end point observed by the $\mathrm{AE}$ characteristics of sensors fixed in the middle of specimens was at $25 \%$ of peak stress. The stress cracking the original microcracks in the ends of the specimens was relatively lower 
than the stress cracking the original microcracks in the waist of the specimens. This result occurred because the original defects at the specimen ends were weaker than that at the waist. The stable growth stage of specimens indicated that the stress was between $10 \%$ and $90 \%$ of ultimate stress by the $\mathrm{AE}$ parameter achieved from sensors fixed on the ends, and the percentages were between $25 \%$ and $85 \%$ according to the $\mathrm{AE}$ parameter achieved from sensors fixed at the waist. For the specimens of cement-stabilized macadam, the crack started from the middle of the specimens and propagated quickly to the ends. Furthermore, the end effect in the compression test also delayed the unstable cracking stress; thus, the stable growth stage was observed for a longer period by the $\mathrm{AE}$ parameter achieved from the sensor fixed on the ends. The unstable stage began from $90 \%$ of ultimate stress summarized by the $\mathrm{AE}$ parameter obtained from the sensor fixed on the ends and began from $85 \%$ of ultimate stress summarized by the $\mathrm{AE}$ parameter obtained from sensors fixed at the waist. In the unstable stage, the cumulative $\mathrm{AE}$ energy and $\mathrm{AE}$ counts recorded by the sensors fixed at the waist were larger than those recorded by sensors fixed on the end because numerous macrocracks had been generated on the waist of the specimens when the cracks propagated to the ends.

According to the above discussion and analysis, the failure process of a semirigid base of dense skeleton type was sensitively monitored by AE technology during the uniaxial compression tests, and the test method of sensors attached to the waist of the specimens was superior to that of the other sensors on reflecting the failure process. The crack state was detected by $\mathrm{AE}$ technology during the uniaxial compression tests in this paper, and the abrupt change of $\mathrm{AE}$ parameter and $b$-value indicated that the microcracks became the macrocracks in the specimens. The crack size was quite difficult to be quantified with $\mathrm{AE}$ analysis of the test. However, the AE detection combined with other detection technology was used to provide more credible information of the structural condition [23]. In future research, likewise, the research of $\mathrm{AE}$ detection combined with the GPR to detect and quantify the crack of semirigid base fast is carried out.

In addition, the variations of $b$-value of all specimens are similar in the same scheme for sensor layouts. Just a couple of $b$-values were analyzed because of limited space of the paper. The $b$-values regarding the crack developing stages are very much depending on the testing conditions. The effect of the testing conditions, for example, rate of loading, on the $b$-value is also a significative research.

\section{Conclusions}

The following conclusions are drawn:

(1) AE parameters can reflect the failure process of a semirigid base of dense skeleton type. The failure process mainly underwent three stages that were divided by $\mathrm{AE}$ parameters into the initial stage of development (early period of loading), stable growth stage (middle period of loading), and unstable stage (end period of loading). The knees of the AE parameter curve occurred at $25 \%$ and $85 \%$ of ultimate load.
(2) The variation of the $b$-value, which changed systematically with the different stages of the failure process, indicates the stress and is a precursor to specimen failure. In general terms, a $b$-value greater than 3.5 indicates that the specimens are at the initial stage of development. A $b$-value that remains stable between 1 and 2 indicates that the specimens are at the stable growth stage. Finally, a fluctuating and increasing $b$ value indicates that the specimens are at the unstable stage.

(3) According to a comparison of the schemes of sensor layouts, the $\mathrm{AE}$ parameters saved by different test methods of position for attaching sensors indicated that the test method of sensors attached to the waist of the specimens reflected the failure process more effectively than that of the other sensors.

\section{Competing Interests}

The authors declare that they have no competing interests.

\section{Acknowledgments}

The authors are grateful for the financial support from the National Natural Science Foundation of China (51208471), Outstanding Young Talent Research Fund of Zhengzhou University (1421322059), Science and Technology Planning Project of Transportation in Henan Province (2016Y2-2), and the Specialized Research Foundation for the Doctoral Program of Higher Education (20114101120008).

\section{References}

[1] D. H. Chen, C. Tang, H.-B. Xiao, and P. Ying, "Utilizing electromagnetic spectrum for subsurface void detection-case studies," Arabian Journal of Geosciences, vol. 8, no. 9, pp. 77057717, 2014.

[2] M. Li, R. Vilbig, R. Birken, D. Busuioc, N. X. Sun, and M. Wang, "Novel miniaturized antenna designs for in-traffic air-coupled ground penetrating radar systems," Journal of Environmental and Engineering Geophysics, vol. 20, no. 1, pp. 71-79, 2015.

[3] M. Shigeishi and M. Ohtsu, "Acoustic emission moment tensor analysis: development for crack identification in concrete materials," Construction and Building Materials, vol. 15, no. 5-6, pp. 311-319, 2001.

[4] X.-J. Tang, J. Xu, and T. Deng, "Research on the rock acoustic emission rules under different experimental conditions," Applied Mechanics and Materials, vol. 170-173, pp. 237-241, 2012.

[5] J.-S. Kim, K.-S. Lee, W.-J. Cho, H.-J. Choi, and G.-C. Cho, "A comparative evaluation of stress-strain and acoustic emission methods for quantitative damage assessments of brittle rock," Rock Mechanics and Rock Engineering, vol. 48, no. 2, pp. 495508, 2014.

[6] M. Rao, D. Murthy, G. Nagaraja Rao, S. K. Mohanty, and S. Udayakumar, "Stress-induced micro-cracking and brittle failure of Godhra granite, Gujarat: a laboratory investigation using acoustic emission," Journal of the Geological Society of India, vol. 64, no. 6, pp. 775-783, 2004. 
[7] Z.-Z. Zhang, F. Gao, and X.-J. Shang, "Rock burst proneness prediction by acoustic emission test during rock deformation," Journal of Central South University, vol. 21, no. 1, pp. 373-380, 2014.

[8] M. S. A. Perera, P. G. Ranjith, and M. Peter, "Effects of saturation medium and pressure on strength parameters of Latrobe Valley brown coal: carbon dioxide, water and nitrogen saturations," Energy, vol. 36, no. 12, pp. 6941-6947, 2011.

[9] P. G. Ranjith, D. Jasinge, S. K. Choi, M. Mehic, and B. Shannon, "The effect of $\mathrm{CO}_{2}$ saturation on mechanical properties of Australian black coal using acoustic emission," Fuel, vol. 89, no. 8, pp. 2110-2117, 2010.

[10] V. Vishal, P. G. Ranjith, and T. N. Singh, "An experimental investigation on behaviour of coal under fluid saturation, using acoustic emission," Journal of Natural Gas Science and Engineering, vol. 22, pp. 428-436, 2015.

[11] Y. Yang, L. Zhang, J. Lv, and C. Wang, "Experimental study on fracture process of concrete by acoustic emission technology," Przeglad Elektrotechniczny, vol. 88, no. 9, pp. 55-58, 2012.

[12] T. K. Haneef, K. Kumari, C. K. Mukhopadhyay, Venkatachalapathy, B. P. Rao, and T. Jayakumar, "Influence of fly ash and curing on cracking behavior of concrete by acoustic emission technique," Construction and Building Materials, vol. 44, pp. 342-350, 2013.

[13] P. G. Ranjith, D. Jasinge, J. Y. Song, and S. K. Choi, "A study of the effect of displacement rate and moisture content on the mechanical properties of concrete: use of acoustic emission," Mechanics of Materials, vol. 40, no. 6, pp. 453-469, 2008.

[14] T. Watanabe, S. Nishibata, C. Hashimoto, and M. Ohtsu, "Compressive failure in concrete of recycled aggregate by acoustic emission," Construction and Building Materials, vol. 21, no. 3, pp. 470-476, 2007.

[15] X. Lei, K. Masuda, O. Nishizawa et al., "Detailed analysis of acoustic emission activity during catastrophic fracture of faults in rock," Journal of Structural Geology, vol. 26, no. 2, pp. 247258, 2004.

[16] X. Lei and T. Satoh, "Indicators of critical point behavior prior to rock failure inferred from pre-failure damage," Tectonophysics, vol. 431, no. 1-4, pp. 97-111, 2007.

[17] M. Rao and K. Lakshmi, "Analysis of b-value and improved b-value of acoustic emissions accompanying rock fracture," Current Science, vol. 89, no. 9, pp. 1577-1582, 2005.

[18] A. Carpinteri, G. Lacidogna, and S. Puzzi, "From criticality to final collapse: evolution of the 'b-value' from 1.5 to 1.0," Chaos, Solitons \& Fractals, vol. 41, no. 2, pp. 843-853, 2009.

[19] A. Carpinteri, G. Lacidogna, and G. Niccolini, "Fractal analysis of damage detected in concrete structural elements under loading," Chaos, Solitons and Fractals, vol. 42, no. 4, pp. 20472056, 2009.

[20] R. V. Sagar and M. V. M. S. Rao, "An experimental study on loading rate effect on acoustic emission based b-values related to reinforced concrete fracture," Construction and Building Materials, vol. 70, pp. 460-472, 2014.

[21] S. Colombo, I. G. Main, and M. C. Forde, "Assessing damage of reinforced concrete beam using 'b-value' analysis of acoustic emission signals," Journal of Materials in Civil Engineering, vol. 15, no. 3, pp. 280-286, 2003.

[22] M. E. Zitto, R. Piotrkowski, A. Gallego, F. Sagasta, and A. Benavent-Climent, "Damage assessed by wavelet scale bands and b-value in dynamical tests of a reinforced concrete slab monitored with acoustic emission," Mechanical Systems and Signal Processing, vol. 60-61, pp. 75-89, 2015.
[23] Y. Wang and H. Hao, "Integrated health monitoring for reinforced concrete beams: an experimental study," Australian Journal of Mechanical Engineering, vol. 8, no. 2, pp. 207-218, 2011. 

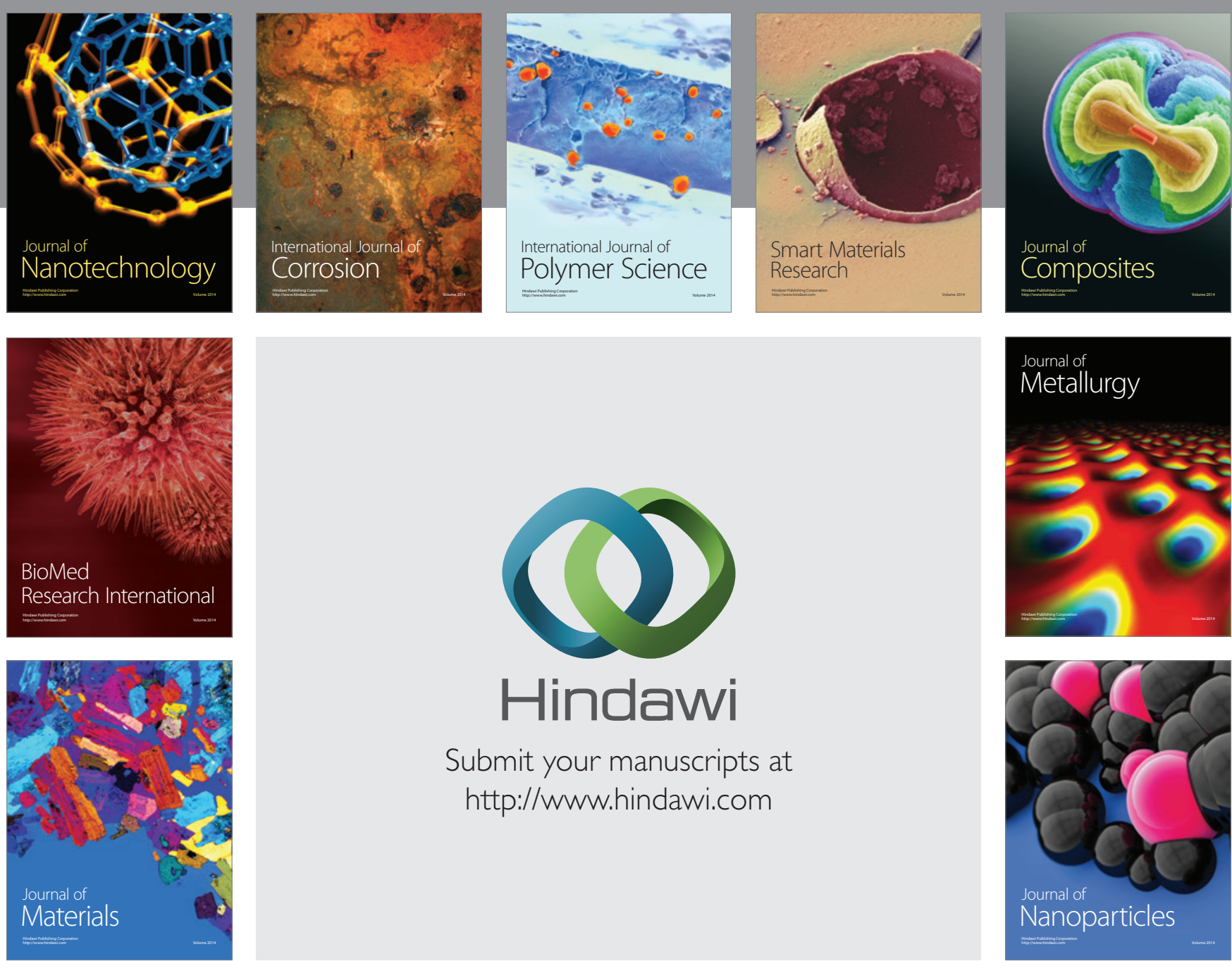

\section{Hindawi}

Submit your manuscripts at

http://www.hindawi.com

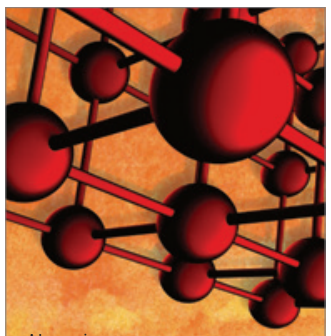

Materials Science and Engineering
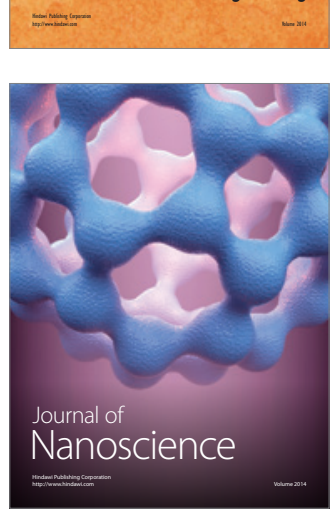
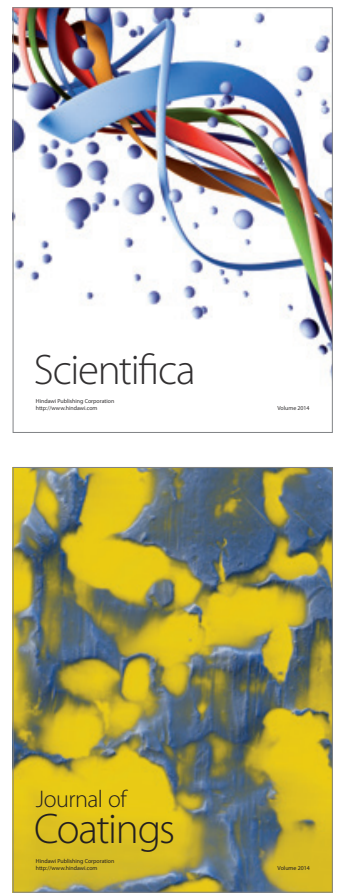
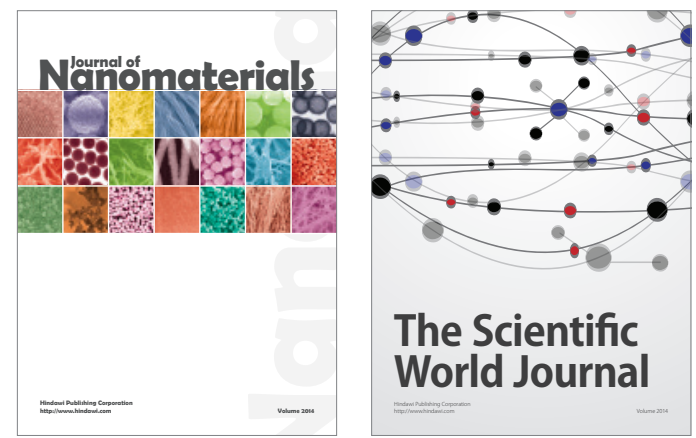

The Scientific World Journal
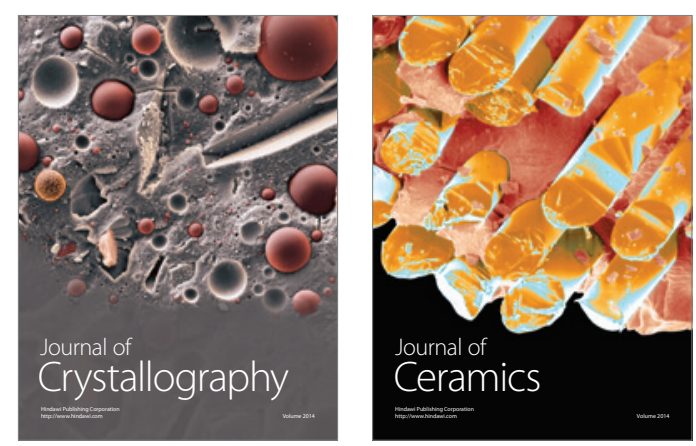
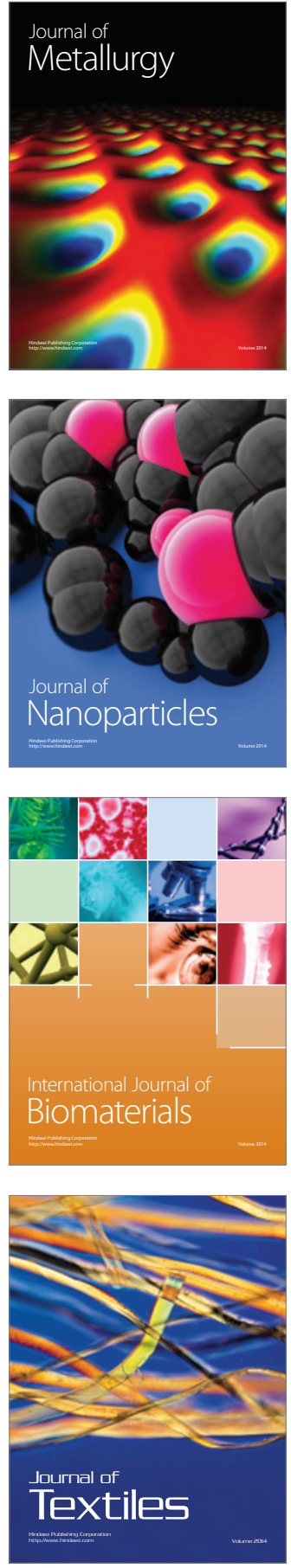